\title{
A two-phase fuzzy programming model for a complex bi-objective no-wait flow shop scheduling
}

\author{
Mahdi Naderi-Beni $^{a^{*}}$, Reza Tavakkoli-Moghaddam ${ }^{\mathrm{b}}$, Bahman Naderi ${ }^{\mathrm{c}}$, Ehsan Ghobadian $^{\mathrm{a}}$ and \\ Alireza Pourrousta ${ }^{a}$
}

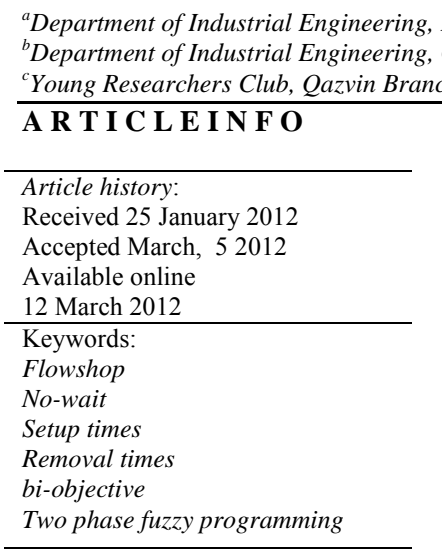

\section{Introduction}

Flowshop is one of the well-known problems, which has attracted many researchers for a while. Manufacturing equipments, which produce one or two similar products using high-volume specialized equipments, are normally considered as an example of flowshop and as an example; we may consider an assembly line (Pinedo, 2008). No-wait flow shop problem (NWFP) is one of the primary restrictions in flowshop problem. According to this limitation, as soon as a job finishes its work on one machine, the operations of the next machine on this job must be initiated and no interruption is permitted. There are many industrial applications of NWFP such as steel industry, plastic injection, chemical and pharmaceutical industries (Hall \& Sriskandarajah, 1996). There are literally various studies associated with NWFP problem. Liu et al. (2007), for instance presented particle swarm optimization to minimize makespan. Pen et al. (2008) presented a discrete PSO along with variable neighborhood descent to minimize makespan and total flowtime for NWFP problem. Tseng and Lin (2010) proposed a hybrid genetic algorithm for no-wait flowshop scheduling problem, which also uses a local search.

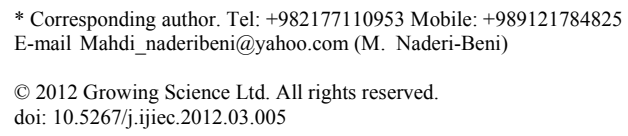


Wang et al. (2010) used accelerated Tabu search for NWFP problem for maximum lateness $\left(L_{\max }\right)$. They increased the basic operations of generating better candidate solutions using Tabu search and reduced the complexity of the operations of NEH. Note that Hall et al. (1996) performed a comprehensive survey of scheduling problems with blocking and no-wait in process. There are many industries where setup times as well as processing times are independent from the operational times. Setup times include the necessary times for adding or exchanging equipments on facilities (Eren, 2009). Setup times and other related times are divided into two groups of independent and dependent times. There are many industrial cases where setup times depend on the operations such producing different colors using some common machines and the problem is called sequence-dependent setup time flow shop problem (SDSTFP).

Based on the notations developed by Graham et al. (1979), Allahvedi et al. (2008), Eren (2007), different metaheuristics based on tabu search, random search for $F_{2}\left|S T_{s i}\right| \alpha \sum C+\beta \sum C_{\max }+$ $\gamma \sum T_{\max }+\theta \sum E_{\max }$ have been developed. There are some mixed integer programming techniques, which can be used to solve problems in small scales. For instance, Eren (2010) presented a mathematical programming to solve $F_{m}\left|S T_{s d}\right| \alpha \sum C+\beta C_{\max }$ for relatively large-scale problems and gave three heuristics to solve the resulted problem. Mirabi (2010) presented a hybrid ant colony to solve $F_{m}\left|S T_{s d}\right| C_{\max }$. For a complete review of the literature, interested readers are referred to Allahverdi et al. (1999, 2008). Franca et al. (2006) proposed a genetic algorithm for $F_{m} \mid r_{j}, S T_{s d}, n o-$ wait $\mid C_{\max }$ and compared the performance of their method with Bianco et al. (1999).

Ruiz and Allahverdi (2007) investigated on SDSTFP problem in a form of $F_{m} \mid S T_{s d}$, no - wait $\mid L_{\text {max }}$. They investigated different heuristics as well as metaheuristics to solve the resulted problem and presented a dominance ratio for three-machine problem. Aldowaisan and Allahverdi (1998) provided a solution methodology for $F_{2} \mid S T_{s d}$, no-wait $\mid \sum C$ and presented one elimination criterion and developed optimal solution for two special cases. Aldowaisan (2001) considered $F_{2} \mid S T_{s d}$, nowait $\mid \sum C$ problem one more time and tried to find a local and global dominance relations. In addition, they proposed some metaheuristics to solve the resulted problem, which seem to provide better quality solutions. They also used branch and bound method to provide a lower bound on this problem. Stafford and Tseng (2002) developed two models for family of flowshop sequencing problems of the form $F_{m} \mid S T_{s d}$, no - wait $\mid C_{\text {max }}$.

Gupta et al. (1997) provided a two-stage operations research models with setup and removal times separated. In their method, they considered setup times independent from operational times and proposed a method for minimizing makespan, which could be solved in polynomial time. Wang and Cheng (2006) proposed a heuristic approach for two-machine no-wait flowshop scheduling with due dates and class setups. They divided jobs to different groups with various setup times with an objective of minimizing the maximum lateness. The proposed model of this paper was developed for multiobjective problems. Jenabi et al. (2010) considered a bi-objective NWFP problem. They first proposed two multi-objective mixed integer programming techniques and presented a local search to find efficient solutions. Javadi et al. (2008) presented fuzzy multi-objective problem for $F_{m} \mid n o-$ wait $\mid \bar{C}, \bar{E}$ to find efficient solutions.

They proposed fuzzy goal programming technique to solve the resulted problem. Fuzzy programming has been considered in different ways to handle uncertainty associated with this type of problem. Ishibuchi et al. (1994) presented local search algorithms for flow shop scheduling with fuzzy due-dates where the primary objective was to maximize the minimum grade of satisfaction. Yao and Feng (2002) constructed a fuzzy flow-shop sequencing model based on statistical data. Wu (2010) presented the fuzzy earliness and tardiness in scheduling problems by using genetic algorithms. They presented a method to minimize the weighted lateness. The concept of fuzzy programming can be also used in 
different areas of scheduling (Gharegozli et al., 2009; Tavakkoli-Moghaddam et al., 2010; KhademiZare \& Fakhrzad, 2011).

In this paper, we present a multi-objective NWFP problem where the first objective is the minimization of weighted average of lateness and the other objective is minimization of makespan. All setup times depend on the sequences of different jobs and machines. We also consider a preliminary setup time when the operations start, which is independent from the sequence of operations and only depends on the machines. The other assumption with the proposed model of this paper is that not all jobs are available at the beginning of the operations. In summary, the proposed model is denoted as $F_{m} \mid$ no wait, $r_{j}, S T_{s d}, R_{s i}, I S T \mid \bar{T}, C_{\text {max }}$. There are literally many real-world applications where we can use the proposed model of this paper (Ruiz et al., 2008). The proposed model of this paper considers two objectives and it is formulated in a form of mixed integer programming and it is solved using the method proposed by Li et al. (2006). The organization of this paper first presents the mathematical model in section 2. The proposed solution methodology is given in section 3 and the performance of the proposed model is examined using different test problems and the results are given in section 4. Finally, concluding remarks are given in the last to summarize the contribution of the paper.

\section{The proposed model}

The proposed model of this paper considers $F_{m} \mid$ no - wait, $r_{j}, S T_{s d}, R_{s i}, I S T \mid \bar{T}, C_{\text {max }}$ where $I S T$ is the initial setup times for processing jobs located in the first stage of operations.

\subsection{Assumptions}

- All parameters are assumed deterministic.

- There must be no interruption when an operation starts on a particular machine.

- All jobs must precede the other operations on other machines as soon as they are finished with a particular machine unless the operations belong to the last machine.

- Each machine can only process one job at the same time.

- Processing times do not depend on sequence and they are all deterministic.

- Not all jobs can be processed at the beginning of the operations.

- All machines are available in planning time horizon and there is no failure or interruption.

- Removal time is independent from the processing and order of sequence and it is predefined.

\section{Sets and indexes}

\begin{tabular}{lll}
\hline$J:$ & Set of jobs & $(J=\{1,2, \ldots, n\} ; n:$ the number of jobs $)$ \\
$I:$ & Set of machines & $(I=\{1,2, \ldots, m\} ;$ m: the number of machines $)$ \\
$P:$ & Set of positions & $(P=\{1,2, \ldots, p\} ; p:$ the number of positions; $n=p)$ \\
$j, k:$ & Job indexes & $(j, k \in J)$ \\
$i:$ & Machine indexes & $(i \in I)$ \\
$p:$ & Index of positions & $(p \in P)$ \\
\hline
\end{tabular}

\section{Parameters}

$w_{j}: \quad$ Weight of job $j$

$r_{j}: \quad$ Release date for job $j$

$d_{j}$ : $\quad$ Due date of job $j$

$p_{j i}$ : $\quad$ Processing time of job $j$ on machine $i$

$r t_{j i}: \quad$ Removal time of job $j$ on machine $i$

$s_{j i k}: \quad \quad \quad$ Setup time of job $k$ on machine $i$ if it is processed immediately after job $j$

ist $_{j i 1}$ : Initial setup time of job $j$ on machine $i$ if the job is in the first position of the sequence.

M: $\quad$ Big number 


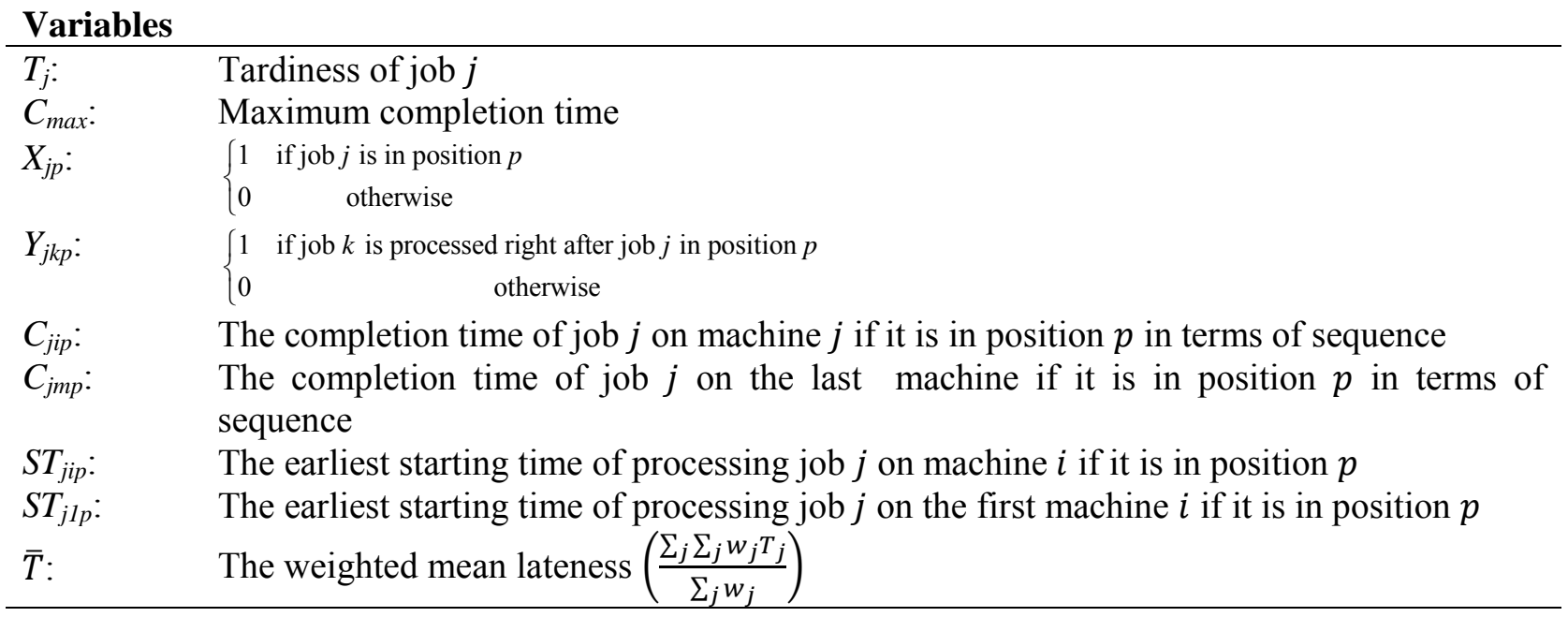

\subsection{The proposed bi-objective mixed integer programming (BMILP)}

$$
\begin{array}{ll}
\min Z_{1}=\bar{T} & \\
\min Z_{2}=C_{\max } & \\
\text { subject to: } & \\
\sum_{j} X_{j p}=1 & ; \forall p \\
\sum_{p} X_{j p}=1 & ; \forall j \\
Y_{j k p} \leq X_{j(p-1)} & ; \forall j, k ; k \neq j ; p \geq 2 \\
Y_{j k p} \leq X_{k p} & ; \forall j, k ; k \neq j ; p \geq 2 \\
\sum_{j} \sum_{k} Y_{j k p}=1 & ; k \neq j ; p \geq 2 \\
S T_{j i p} \geq r_{j} . X_{j p} & ; \forall j, i, p \\
S T_{j i p} \geq i s t_{j i 1} \cdot X_{j p} & ; p=1 ; \forall j, i \\
S T_{k 1 p}-S T_{j 1(p-1)}+M\left(1-Y_{j k p}\right) \geq s_{j 1 k}+p_{j 1}+r t_{j 1} & ; \forall j, k ; k \neq j ; p \geq 2 \\
C_{j i p}=S T_{j i p}+\left[p_{j i} . X_{j p}\right] & ; i=1 ; \forall j, p \\
C_{j i p}=C_{j(i-1) p}+\left[p_{j i} . X_{j p}\right] & ; i \geq 2 ; \forall j, p \\
C_{k i p}-C_{j i(p-1)}+M\left(1-Y_{j k p}\right) \geq S_{j i k}+p_{k i}+r t_{j i} & ; \forall j, k ; k \neq j ; p \geq 2 \\
S T_{j i p} \leq M X_{j p} & ; \forall j, i, p \\
C_{j i p} \leq M X_{j p} & ; \forall j, i, p \\
C_{m a x} \geq C_{j m p} & ; \forall j, p \\
T_{j} \geq C_{j i p}-d_{j} & ; \forall j, i, p \\
X_{j p} \in\{0,1\} & ; \forall j, p \\
Y_{j k p} \in\{0,1\} & ; \forall k, j ; k \neq j \\
T_{j}, S T_{j i p}, C_{j i p} \geq 0 & ; \forall j, i, p
\end{array}
$$

Eq. (1) and Eq. (2) are associated with minimization of weighted mean tardiness and makespan, respectively. Eq. (3) determines that in each position only one job can be located and Eq. (4) guarantees that each job can be only in one position. According to Eq. (5) and Eq. (6), $Y_{j k p}$ is equal to one if both $X_{j p}$ and $X_{j(p-1)}$ are equal to one. Eq. (7) indicates that for each position $(p \geq 2)$ only one job can be started after another one. Eq. (8) indicates that the earliest time for processing job $j$ on machine $i$ cannot be less than its release date $r_{\mathrm{j}}$. Eq. (9) guarantees that earliest time to process job $\mathrm{j}$ cannot be sooner than its initial setup time if job $j$ is in the first position of sequence. Eq. (10) indicates that there is no interruption between jobs and machines. Eq. (11) computes the completion time of job $j$ on the first machine if job $j$ is located in position $p$ in terms of sequence. Eq. (12) computes the completion times of job $\mathrm{j}$ on the second machine and after and it guarantees that there is no interruption. Eq. (13) 
shows the relationship between completion times of two sequential jobs. According to Eq. (14) and Eq. (15), we can make sure that if job $j$ in not in position $p$ then the earliest starting and completion times are equal to zero, otherwise, $X_{j p}=1$. Eq. (16) shows that makespan cannot be less than completion time of the last machine. Eq. (17) is also associated with the tardiness of job $j$. Finally, Eqs. (18-20) show variable types definitions.

\section{The proposed model}

The proposed model of this paper uses a two-stage fuzzy programming, which is based on the method developed by Li et al. (2006) and the first stage uses Zimmerman's method (Zimmerman, 1978). We first present the necessary notations associated with the proposed model.

\subsection{Notations}

$\lambda: \quad$ Satisfaction degree

$\lambda_{-}$PH1: $\quad$ Satisfaction degree after the first stage

$\lambda \_P H 2: \quad$ Satisfaction degree after the second stage

$\lambda_{f}: \quad$ Satisfaction degree of the $f^{\text {th }}$ objective function after the second stage $(f=1,2)$

$v_{f}$ : $\quad$ weight of satisfaction degree of the $f^{\text {th }}$ objective function in the second stage $(f=1,2)$

$z_{1}^{l}$ : $\quad$ The lower bound of the first objective function

$z_{2}^{l}$ : The lower bound of the second objective function

$z_{1}^{u}$ : The value of the first objective function when the second objective function has the minimum value $\left(z_{1}^{\mathrm{u}}>\mathrm{z}_{1}^{\mathrm{l}}\right)$

$z_{2}^{u}$ : The value of the second objective function when the first objective function has the minimum value $\left(z_{2}^{\mathrm{u}}>\mathrm{z}_{2}^{\mathrm{l}}\right)$

$z_{1}^{0}$ : $\quad$ The value of the first objective function after the first stage terminates

$z_{2}^{0}$ : The value of the second objective function after the first stage terminates

\subsection{Solution procedure}

\subsubsection{Phase one}

Step 1. The proposed BMILP is solved based on $Z_{1}$ and the optimal value is called $Z_{1}^{\mathrm{l}}$.

Step 2. Based on the solution obtained from the first step, $Z_{2}^{u}$ is computed.

Step 3. The proposed BMILP is solved based on $Z_{2}$ and the optimal value is called $Z_{2}^{\mathrm{l}}$.

Step 4. Based on the solution obtained from the third step, $Z_{1}^{u}$ is computed.

Step 5. Solve the following linear programming problem.

$\max \lambda$

subject to:

$$
\begin{aligned}
& \bar{T} \leq z_{1}^{u}-\lambda\left(z_{1}^{u}-z_{1}^{l}\right) \\
& C_{\max } \leq z_{2}^{u}-\lambda\left(z_{2}^{u}-z_{2}^{l}\right) \\
& \lambda \in[0,1]
\end{aligned}
$$

Constraints (5-19) 
Step 6. Set $\lambda \_P H 1$ to computed $\lambda$ in step 5 .

\subsubsection{Phase two}

Step 7. Compute $\bar{T}, C_{\max }$ based on the results of step 5 and store them in $Z_{1}^{0}$ and $Z_{2}^{0}$, respectively. Solve the following linear programming problem,

$\max \mathrm{v}_{1} \lambda_{1}+\mathrm{v}_{2} \lambda_{2}$

subject to

$$
\begin{aligned}
& \bar{T} \leq z_{1}^{u}-\lambda_{1}\left(z_{1}^{u}-z_{1}^{l}\right) \\
& \lambda_{1} \geq \frac{z_{1}^{u}-z_{1}^{0}}{z_{1}^{u}-z_{1}^{l}} \\
& C_{\max } \leq z_{2}^{u}-\lambda_{2}\left(z_{2}^{u}-z_{2}^{l}\right) \\
& \lambda_{2} \geq \frac{z_{2}^{u}-z_{2}^{0}}{z_{2}^{u}-z_{2}^{l}} \\
& v_{1}+v_{2}=1 \\
& \lambda_{1}, \lambda_{2} \in[0,1] \\
& \text { Constraints (5-19) }
\end{aligned}
$$

Step 8. $\lambda \_P H 2$ is equal to optimal value obtained from Eq. (26) achieved from step 7.

Step 9. Repeat computations to calculate $\bar{T}$ and $C_{\max }$ until the final solutions are achieved.

\section{Numerical examples}

In order to measure the relative efficiency of the proposed model of this paper, we have solved 102 randomly generated test problems. Except $v_{1}$ and $v_{2}$, which are determined by decision maker, all other values are predefined. Table 1 shows details of our input parameters.

\section{Table 1}

The method of generating input parameters

\begin{tabular}{lc}
\hline Parameters & Values \\
\hline The number of machines $(m)$ & $2,3,4$ \\
The number of jobs $(n)$ & $6,7,8$ \\
Processing time $\left(p_{j i}\right)$ & $\sim D U[1,50]$ \\
Release date $\left(r_{j}\right)$ & $\sim D U[0.100]$ \\
Due date $\left(d_{j}\right)$ & $\left.\sim m\left(\frac{\sum \sum p_{j i}}{m n}\right)+\frac{\sum \sum \sum s_{j i k}}{m n^{2}}+\frac{\sum \sum i s t_{j i 1}}{m n}+m\left(\frac{\sum \sum r t_{j i}}{m n}\right)+r_{j}\right]+1$ \\
Weight $\left(w_{j}\right)$ & $\sim D U[1,17]$ \\
Removal time $\left(r t_{j i}\right)$ & $\sim D U[1,17]$ \\
Setup time $\left(s_{j i k}\right)$ & $\sim D U[1,25]$ \\
Initial setup time $\left(i s t_{j i 1}\right)$ & 0.5 \\
$v_{1}=v_{2}$ & $3 \times 3 \times 5=45$ \\
Total problem & $\times D U$ \\
\hline
\end{tabular}

\subsection{Discussion}


In this section, we discuss the performance of the proposed model of this paper and compare the performance of two phase fuzzy method with Zimmerman's approach. We have solved all our test problems using LINGO-8 and the results are summarized in Table 2, Table 3 and Table 4.

\section{Table 2}

Results for 2-machine problems

\begin{tabular}{|c|c|c|c|c|c|c|c|}
\hline $\begin{array}{l}\text { Number of } \\
\text { machines }\end{array}$ & $\begin{array}{l}\text { Number } \\
\text { of jobs }\end{array}$ & $\begin{array}{c}\text { Number of } \\
\text { test }\end{array}$ & $\begin{array}{c}\lambda \text { of phase } 1 \\
\left(\lambda \_ \text {PH1) }\right.\end{array}$ & $\begin{array}{c}\lambda \text { of phase } 2 \\
\left(\lambda \_\mathrm{PH} 1\right)\end{array}$ & $\begin{array}{c}\text { Objectives values of } \\
\text { phase } 1 \\
\left(\bar{T}, C_{\max }\right) \\
\end{array}$ & $\begin{array}{c}\text { Objectives values of } \\
\text { phase } 2 \\
\left(\bar{T}, C_{\max }\right) \\
\end{array}$ & $\begin{array}{c}\text { Improvement } \\
\text { in objectives } \\
\text { values } \\
\end{array}$ \\
\hline \multirow[t]{15}{*}{2} & 6 & 1 & 0.900 & 0.917 & $(33.533,305)$ & $(33.533,305)$ & No \\
\hline & & 2 & 0.297 & 0.379 & $(65.476,314)$ & $(65.476,311)$ & Yes \\
\hline & & 3 & 0.714 & 0.814 & $(52.963,302)$ & $(52.963,302)$ & No \\
\hline & & 4 & 0.431 & 0.599 & $(71.792,331)$ & $(71.792,320)$ & Yes \\
\hline & & 5 & 0.384 & 0.513 & $(72.844,334)$ & $(72.844,330)$ & Yes \\
\hline & 7 & 1 & 0.737 & 0.772 & $(59.342,358)$ & $(57.368,358)$ & Yes \\
\hline & & 2 & 0.741 & 0.759 & $(60.089,295)$ & $(58.489,295)$ & Yes \\
\hline & & 3 & 0.660 & 0.713 & $(64.65,343)$ & $(64.65,336)$ & Yes \\
\hline & & 4 & 0.500 & 0.571 & $(74.586,416)$ & $(74.448,416)$ & Yes \\
\hline & & 5 & 0.556 & 0.563 & $(63.407,351)$ & $(63.407,351)$ & No \\
\hline & 8 & 1 & 0.627 & 0.767 & $(70.830,459)$ & $(70.830,459)$ & No \\
\hline & & 2 & 0.420 & 0.467 & $(60.830,420)$ & $(60.830,413)$ & Yes \\
\hline & & 3 & 0.579 & 0.757 & $(85.587,398)$ & $(81.239,398)$ & Yes \\
\hline & & 4 & 0.750 & 0.781 & $(58.745,348)$ & $(58.745,348)$ & No \\
\hline & & 5 & 0.722 & 0.755 & $(44.789,363)$ & $(44.000,363)$ & Yes \\
\hline
\end{tabular}

Table 3

Results for 3-machine problems

\begin{tabular}{|c|c|c|c|c|c|c|c|}
\hline $\begin{array}{l}\text { Number of } \\
\text { machines }\end{array}$ & $\begin{array}{l}\text { Number } \\
\text { of jobs }\end{array}$ & $\begin{array}{c}\text { Number of } \\
\text { test }\end{array}$ & $\begin{array}{c}\lambda \text { of phase } 1 \\
\left(\lambda \_ \text {PH1) }\right.\end{array}$ & $\begin{array}{c}\lambda \text { of phase } 2 \\
\left(\lambda \_\mathrm{PH} 2\right)\end{array}$ & $\begin{array}{c}\text { Objectives values of } \\
\text { phase } 1 \\
\left(\overline{\mathrm{T}}, \mathrm{C}_{\max }\right) \\
\end{array}$ & $\begin{array}{c}\text { Objectives values of } \\
\text { phase } 2 \\
\left(\overline{\mathrm{T}}, \mathrm{C}_{\max }\right)\end{array}$ & $\begin{array}{c}\text { Improvement } \\
\text { in objectives } \\
\text { values } \\
\end{array}$ \\
\hline \multirow[t]{15}{*}{3} & 6 & 1 & 0.533 & 0.594 & $(50.263,317)$ & $(43.688,317)$ & Yes \\
\hline & & 2 & 0.755 & 0.801 & $(40.333,298)$ & $(40.333,296)$ & Yes \\
\hline & & 3 & 0.475 & 0.593 & $(47.684,347)$ & $(43.895,347)$ & Yes \\
\hline & & 4 & 0.465 & 0.625 & $(66.273,345)$ & $(66.273,340)$ & Yes \\
\hline & & 5 & 0.579 & 0.640 & $(58.879,390)$ & $(58.879,390)$ & No \\
\hline & 7 & 1 & 0.551 & 0.627 & $(97.206,412)$ & $(82.5,412)$ & Yes \\
\hline & & 2 & 0.778 & 0.836 & $(73.788,427)$ & $(73.788,418)$ & Yes \\
\hline & & 3 & 0.428 & 0.507 & $(45.767,375)$ & $(45.767,367)$ & Yes \\
\hline & & 4 & 0.555 & 0.635 & $(52.118,408)$ & $(52.118,404)$ & Yes \\
\hline & & 5 & 0.243 & 0.312 & $(72.364,448)$ & $(72.364,442)$ & Yes \\
\hline & 8 & 1 & 0.475 & 0.679 & $(93.796,442)$ & $(93.796,435)$ & Yes \\
\hline & & 2 & 0.404 & 0.450 & $(71.245,427)$ & $(68.981,427)$ & Yes \\
\hline & & 3 & 0.384 & 0.387 & $(74.889,441)$ & $(74.889,440)$ & Yes \\
\hline & & 4 & 0.750 & 0.817 & $(67.265,418)$ & $(67.265,418)$ & No \\
\hline & & 5 & 0.772 & 0.781 & $(68.870,429)$ & $(68.870,427)$ & Yes \\
\hline
\end{tabular}

\section{Table 4}

Results for 4-machine problems

\begin{tabular}{|c|c|c|c|c|c|c|c|}
\hline $\begin{array}{l}\text { Number of } \\
\text { machines }\end{array}$ & $\begin{array}{l}\text { Number of } \\
\text { jobs }\end{array}$ & $\begin{array}{l}\text { Number of } \\
\text { test }\end{array}$ & $\begin{array}{c}\lambda \text { of phase } 1 \\
\left(\lambda \_ \text {PH1) }\right.\end{array}$ & $\begin{array}{c}\lambda \text { of phase } 2 \\
\left(\lambda \_ \text {PH1) }\right.\end{array}$ & $\begin{array}{c}\text { Objectives values of } \\
\text { phase } 1 \\
\left(\overline{\mathrm{T}}, \mathrm{C}_{\max }\right)\end{array}$ & $\begin{array}{c}\text { Objectives values of } \\
\text { phase } 2 \\
\left(\overline{\mathrm{T}}, \mathrm{C}_{\max }\right)\end{array}$ & $\begin{array}{c}\text { Improvement } \\
\text { in objectives } \\
\text { values }\end{array}$ \\
\hline \multirow[t]{15}{*}{4} & 6 & 1 & 0.324 & 0.638 & $(45.472,427)$ & $(45.672,400)$ & Yes \\
\hline & & 2 & 0.243 & 0.590 & $(53.256,391)$ & $(53.256,368)$ & Yes \\
\hline & & 3 & 0.557 & 0.716 & $(56.027,400)$ & $(56.027,387)$ & Yes \\
\hline & & 4 & 0.696 & 0.765 & $(74.263,410)$ & $(74.263,408)$ & Yes \\
\hline & & 5 & 0.533 & 0.535 & $(60.65,374)$ & $(60.65,374)$ & No \\
\hline & 7 & 1 & 0.625 & 0.653 & $(69.341,482)$ & $(69.431,480)$ & Yes \\
\hline & & 2 & 0.704 & 0.736 & $(48.829,380)$ & $(48.829,377)$ & Yes \\
\hline & & 3 & 0.571 & 0.620 & $(81.697,477)$ & $(74.485,477)$ & Yes \\
\hline & & 4 & 0.545 & 0.547 & $(65.151,446)$ & $(65.151,445)$ & Yes \\
\hline & & 5 & 0.500 & 0.613 & $(102.389,453)$ & $(102.389,453)$ & No \\
\hline & 8 & 1 & 0.909 & 0.942 & $(50.855,401)$ & $(49.873,401)$ & Yes \\
\hline & & 2 & 0.612 & 0.682 & $(158.568,523)$ & $(88.864,523)$ & Yes \\
\hline & & 3 & 0.130 & 0.322 & $(98.841,512)$ & $(96.884,512)$ & Yes \\
\hline & & 4 & 0.393 & 0.562 & $(74.553,489)$ & $(72.319,489)$ & Yes \\
\hline & & 5 & 0.508 & 0.592 & $(84.725,505)$ & $(46.025,505)$ & Yes \\
\hline
\end{tabular}


As we can observe from the results of Tables, the level of satisfaction degree of phase 2 is relatively better than the first level. In addition, Li et al. (2006) proved that the level of second level satisfaction will not be worse than the first level. Besides, 36 out of 45 sample test problems yields better results, which implies that the two-phase method performs better than the Zimmerman's method. Table 5 shows details of our results for different values of $v_{1}$ and $v_{2}$. As we can observe the final solutions are sensitive to all these values.

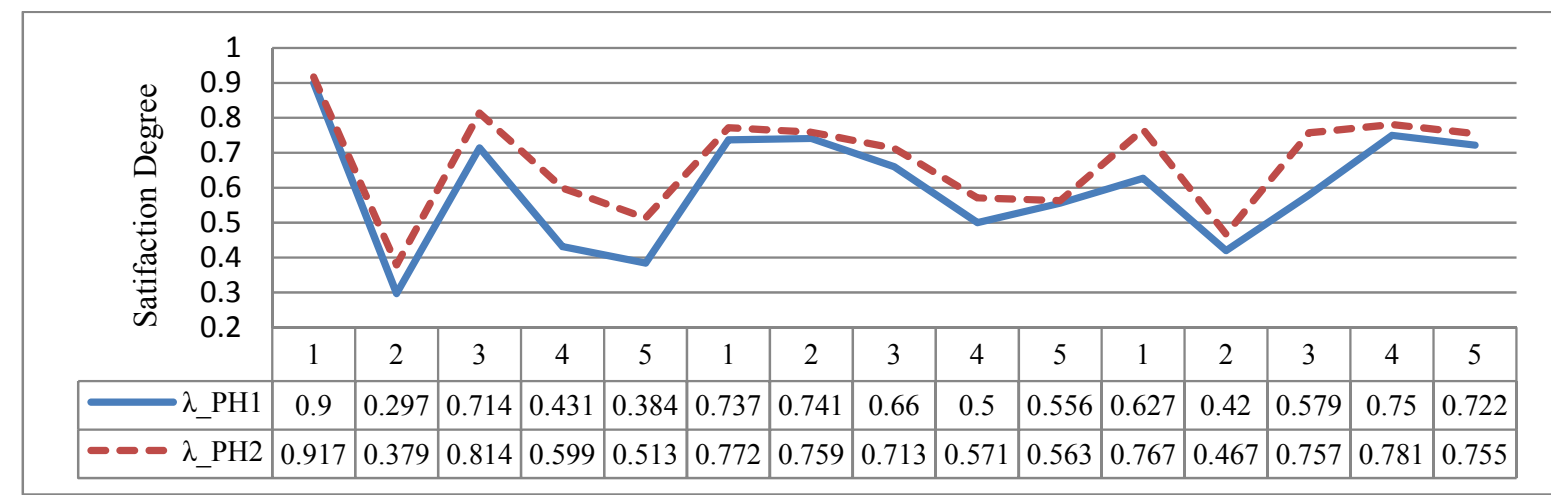

Fig. 1. Comparison between satisfaction degrees of phase one and phase two for 2-machine problems



Fig .2. Comparison between satisfaction degrees of phase one and phase two for 3-machine problems

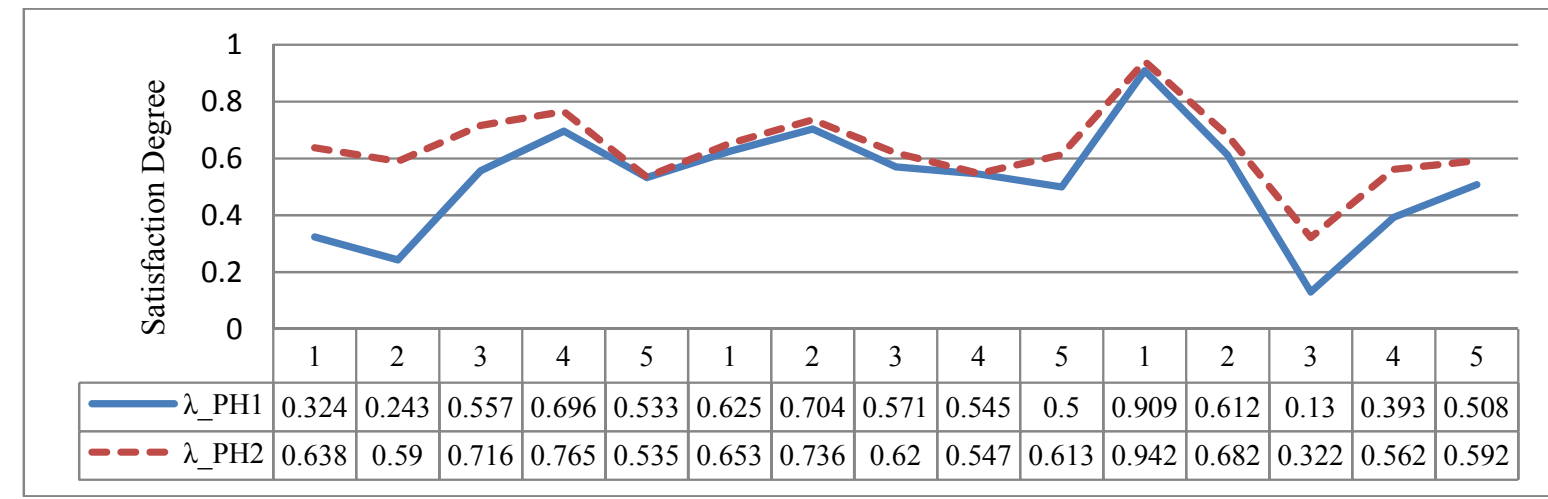

Fig .3. Comparison between satisfaction degrees of phase one and phase two for 4-machine problems

\section{Conclusions}

In this paper, we have presented a no-wait flow shop problem where setup times depend on sequence of operations. The proposed problem considered sequence-independent removal times, release date with an additional assumption that there were some preliminary setup times. There were two objectives of weighted mean tardiness and makespan associated with the proposed model of this paper. The proposed model of this paper formulated the resulted problem as a mixed integer programming, where a two phase fuzzy programming was implemented to solve the model. To examine the performance of the proposed model, we have generated 
several sample data, randomly and compared the results with other methods. The results indicated that the proposed two-phase model of this paper performed relatively better than Zimmerman's single phase fuzzy method.

\section{Table 5}

The result of the implementation of the proposed 2-phase fuzzy programming with changing in value of $v_{1}$

\begin{tabular}{|c|c|c|c|c|c|c|c|c|c|c|}
\hline \multirow{2}{*}{\multicolumn{2}{|c|}{ Phase-1 }} & \multicolumn{3}{|c|}{$m=2, n=6$} & \multicolumn{3}{|c|}{$\mathrm{m}=3, \mathrm{n}=6$} & \multicolumn{3}{|c|}{$m=4, n=6$} \\
\hline & & $\bar{T}$ & $C_{\max }$ & $\lambda$ & $\bar{T}$ & $C_{\max }$ & $\lambda$ & $\bar{T}$ & $C_{\max }$ & $\lambda$ \\
\hline \multirow{19}{*}{ 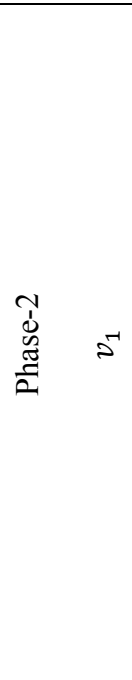 } & 0.05 & 42.400 & 294 & 0.248 & 64.286 & 377 & 0.614 & 61.763 & 441 & 0.804 \\
\hline & 0.10 & 42.400 & 294 & 0.246 & 64.286 & 377 & 0.620 & 61.763 & 441 & 0.802 \\
\hline & 0.15 & 42.400 & 294 & 0.244 & 64.286 & 377 & 0.625 & 61.763 & 441 & 0.800 \\
\hline & 0.20 & 42.400 & 294 & 0.242 & 64.286 & 377 & 0.631 & 61.763 & 441 & 0.798 \\
\hline & 0.25 & 42.400 & 294 & 0.240 & 64.286 & 377 & 0.636 & 61.763 & 441 & 0.795 \\
\hline & 0.30 & 42.400 & 294 & 0.237 & 64.286 & 377 & 0.642 & 61.763 & 441 & 0.793 \\
\hline & 0.35 & 42.400 & 294 & 0.235 & 64.286 & 377 & 0.647 & 61.763 & 441 & 0.791 \\
\hline & 0.40 & 42.400 & 294 & 0.233 & 64.286 & 377 & 0.653 & 61.763 & 441 & 0.789 \\
\hline & 0.45 & 42.400 & 294 & 0.231 & 64.286 & 377 & 0.658 & 61.763 & 441 & 0.786 \\
\hline & 0.50 & 42.400 & 294 & 0.229 & 64.286 & 377 & 0.664 & 61.763 & 441 & 0.784 \\
\hline & 0.55 & 42.400 & 294 & 0.227 & 64.286 & 377 & 0.669 & 61.763 & 441 & 0.782 \\
\hline & 0.60 & 42.400 & 294 & 0.225 & 64.286 & 377 & 0.675 & 61.763 & 441 & 0.780 \\
\hline & 0.65 & 42.400 & 294 & 0.223 & 64.286 & 377 & 0.680 & 61.763 & 441 & 0.778 \\
\hline & 0.70 & 42.400 & 294 & 0.221 & 64.286 & 377 & 0.686 & 61.763 & 441 & 0.775 \\
\hline & 0.75 & 42.400 & 294 & 0.219 & 64.286 & 377 & 0.691 & 61.763 & 441 & 0.773 \\
\hline & 0.80 & 42.400 & 294 & 0.217 & 64.286 & 377 & 0.697 & 61.763 & 441 & 0.771 \\
\hline & 0.85 & 42.400 & 294 & 0.215 & 64.286 & 377 & 0.702 & 61.763 & 441 & 0.769 \\
\hline & 0.90 & 42.400 & 294 & 0.212 & 64.286 & 377 & 0.708 & 61.763 & 441 & 0.767 \\
\hline & 0.95 & 42.400 & 294 & 0.210 & 64.286 & 377 & 0.713 & 61.763 & 441 & 0.764 \\
\hline
\end{tabular}
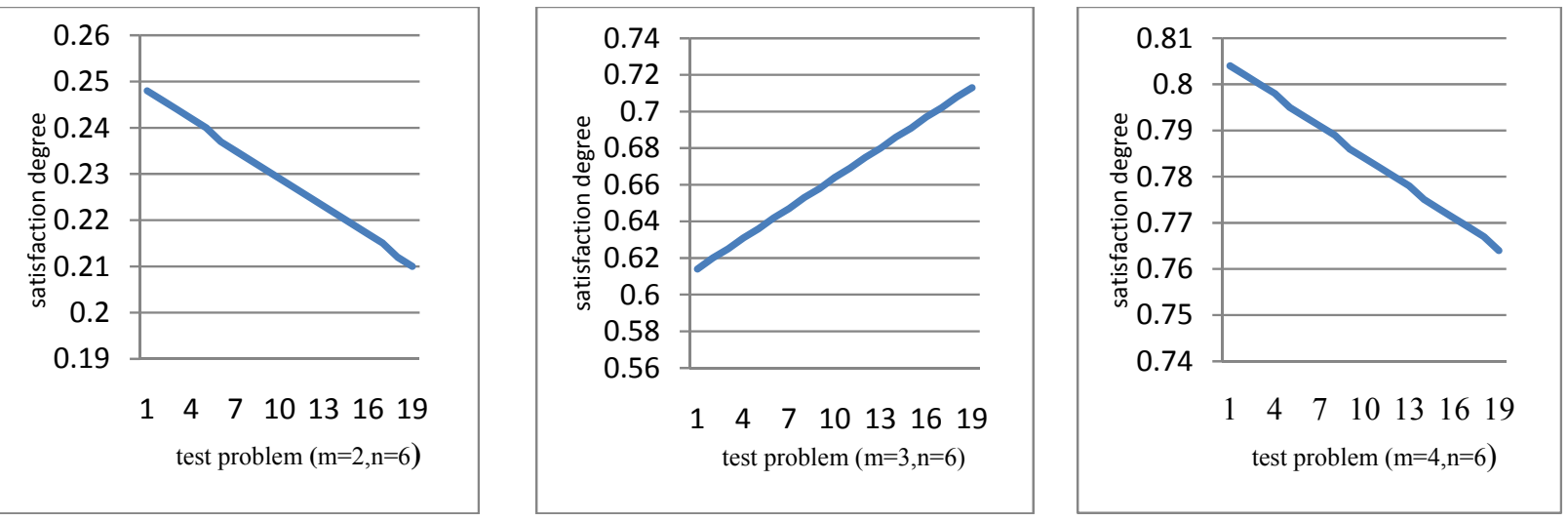

Fig. 4. The impact of the changes in $v_{1}$ on satisfaction degree of phase two

\section{References}

Aldowaisan, T., \& Allahverdi, A. (1998). Total flowtime in no-wait flowshops with separated setup times. Computers \& Operation Research, 25, 757-765.

Aldowaisan, T. (2001). A new heuristic and dominance relations for no-wait flow shops with setups. Computers \& Operations Research, 28, 563-584.

Allahverdi, A., Gupta, J.N.D., \& Aldowaisan, T. (1999). A review of scheduling research involving setup considerations. Omega, The International Journal of Management science, 27, $219-239$.

Allahvedi, A., Ng, C.T., Cheng, T.C.E., \& Kovalyov, M.Y. (2008). A survey of scheduling problems with setups or costs. European Journal of Operational Research, 187, 985-1032.

Bianco, L., Dell'Olmo, P., \& Giordani.S. (1999). Flowshop no-wait scheduling with sequence dependent setup times and release dates. INFOR, 37, 3-19.

Eren, T. (2007). A multicriteria flowshop scheduling problem with setup times. Journal of Materials Processing Technology, 186, 60-65. 
Eren, T. (2009). A bicriteria parallel machine scheduling with a learning effect of setup and removal times. Applied Mathematical Programming, 33, 1141-1150.

Eren, T. (2010). A bicriteria m-machine flowshop scheduling with sequence-dependent setup times. Applied Mathematical Programming, 34, 284-293.

Franca, P.M., Tin, Jr.G., \& Buriol, L.S. (2006). Genetic algorithms for the no-wait flowshop sequencing problem with time restrictions. International Journal of Production Research, 44(5), 939-957.

Gharegozli, A.H., Tavakkoli-Moghaddam, R., \& Zaerpour, N. (2009). A fuzzy-mixed-integer goal programming model for a parallel-machine scheduling problem with sequence-dependent setup times and release dates. Robotics and Computers-Integrated Manufacturing, 25, 853-859.

Graham, R.L., Lawler, E.L., Lenstra, J.K., \& Rinnooy Kan, A.H.G. (1979). Optimization and approximation in deterministic sequencing and scheduling: A survey. Annals of Discrete Mathematics, 5, 287-326.

Gupta, J.N.D., Strusevich, V.A., \& Zwaneveld, C.M. (1997). Two-stage operations research models with setup and removal times separated. Computers \& Operations Research, 24(11), 1025-1031.

Hall, N.G., \& Sriskandarajah, C. (1996). A survey of scheduling problems with blocking and no-wait in process. Operations Research, 44, 510-525.

Ishibuchi, H., Yamamoto, M., Misaki, S., \& Tanaka, H. (1994). Local search algorithms for flow shop scheduling with fuzzy due-dates. International Journal of Production Economics, 33, 53-66.

Javadi, B., Saidi-Mehrabad, M., Haji, A., Mahdavi, I., Jolai, F., \& Mahdavi-Amiri, N. (2008). No-wait flow shop scheduling using fuzzy multi-objective linear programming. Journal of Franklin Institute, 345, 452-467.

Jenabi, M., Naderi, B., \& Ghomi, S.M.T.F. (2010). A bi-objective case of no-wait flowshops. IEEE, Changsha, 1048-1056.

Khademi-Zare, H., \& Fakhrzad, M.B. (2011). Solving flexible flow-shop problem with a hybrid genetic algorithm and data mining: A fuzzy approach. Expert Systems with Applications, 38(6), 7609-7615.

Li, X.Q., Zhang, B., \& Li, H. (2006). Computing efficient solutions to fuzzy multiple objective linear programming problems. Fuzzy Sets and Systems, 157, 1328-1332.

Liu, B., Wang, L., \& Jin, Y.H. (2007). An effective hybrid particle swarm optimization for no-wait flow shop scheduling. International Journal of Advanced Manufacturing Technology, 31, 1001-1011.

Mirabi, M. (2010). Ant colony optimization technique for the sequence-dependent flowshop scheduling problem. International Journal of Advanced Manufacturing Technology, 55(1-4), 317-326.

Pan, Q.K., Tasgetiren, M.F., \& Liang, Y.C. (2008). A discrete particle swarm optimization algorithm for the nowait flowshop scheduling problem. Computers \& Operations Research, 35, 2807-2839.

Pinedo, M.L. (2008). Scheduling: Theory Algorithms and Systems. Third Edition, Springer.

Ruiz, R., \& Allahverdi, A. (2007). No-wait flowshop with separated setup times to minimize maximum lateness. International Journal of Advanced Manufacturing Technology, 35, 551-565.

Ruiz, R., Serifoglu, F.S., \& Urlings, T. (2008). Modeling realistic hybrid flexible flowshop scheduling problems. Computer \& Operations Research, 35, 1151-1175.

Stafford, E.F., \& Tseng, F.T. (2002). Two models for family of flowshop sequencing problems. European Journal of Operational Research, 142, 282-293.

Tavakkoli-Moghaddam, R., Javadi, B., Jolai, F., \& Ghodratnama, A. (2010). The use of a fuzzy multi-objective linear programming for solving a multi-objective single machine scheduling problem. Applied Soft Computing, 10, 919-925.

Tseng, L.Y., \& Lin, Y.T. (2010). A hybrid genetic algorithm for no-wait flowshop scheduling problem. International Journal of Production Economics, 128, 144-152.

Wang, C., Li, X., \& Wang, Q. (2010). Accelerated tabu search for no-wait flowshop scheduling problem with maximum lateness criterion. European Journal of Operational Research, 206, 64-72.

Wang, X., \& Cheng, T.C.E. (2006). A heuristic approach for two-machine no-wait flowshop scheduling with due dates and class setups. Computers \& Operations Research, 33, 1326-1344.

Wu, H.C. (2010). Solving the fuzzy earliness and tardiness in scheduling problems by using genetic algorithms. Expert Systems with Applications, 37, 4860-4866.

Yao, J.S., \& Feng, T.S. (2002). Constructing a fuzzy flow-shop sequencing model based on statistical data. International Journal of Approximate Reasoning, 29, 215-234.

Zimmerman.H.J., (1978), Fuzzy programming with several objective functions, Fuzzy Sets and Systems, 1, 4555. 